\title{
Allergic proctocolitis causing hematochezia in preterm twins
}

\author{
Bipin Karki', Varsha Verma', Ritesh Shrestha ${ }^{2}$, Suchita Shrestha Joshi ${ }^{1 *}$ \\ 'Department of neonatology, Nepal Mediciti Hospital ${ }^{2}$ Fellow pediatric surgery, Department of surgery, Nepal Mediciti Hospital
}

\begin{abstract}
This work is licensed under a Creative Commons Attribution 4.0 Unported License.

Allergic colitis due to cow's milk or soy protein in commercially prepared infant formula or due to ingestion of breast-milk of mothers who are ingesting cow's milk is a known cause of colitis occurring in infants. Allergic colitis can occur within days, weeks or months of birth and should be considered as a differential diagnosis in any infant presenting with hematochezia. Typically, there is a significant delay in the onset of milk allergy in premature infants compared to full term infants. We report a case of premature twin neonates who presented with profuse rectal bleeding during second week of life. The infants had been feeding expressed breast milk since birth and the nursing mother had been drinking cow's milk. The infants had pneumatosis coli suggestive of inflammation of the colon while biochemical and hematological markers of inflammation were normal. Expressed breast milk was re-introduced after eliminating dairy from mother's diet for 5 days. The infants were fed on mother's milk and top up of hydrolyzed infant formula as required. Both the twins remained well.
\end{abstract}

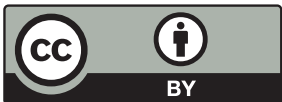

\section{KEYWORDS}

Allergy, hematochezia, infant, proctocolitis, rectal bleeding

\section{ACKNOWLEDGEMENT}

Department of radiology, Nepal Mediciti Hospital

\section{BACKGROUND}

Allergic colitis is a non- IgE, immune mediated gastrointestinal disorder. ${ }^{1}$ The most common associated antigen is cow's milk protein, although other food proteins, notably soy, egg, nuts, fish have also been implicated. Approximately $0.5 \%$ to $1 \%$ of exclusively breastfed infants develop allergic reaction to cow's milk protein excreted in mother's milk. ${ }^{2}$ Cow's milk protein is considered to be the offending antigen in as many as $50-60 \%$ cases. ${ }^{3,4}$ This condition is often overlooked in differential diagnosis leading not only to extended suffering of infants and their families but also unnecessary investigations.

The most common gastrointestinal symptom in allergic colitis is the presence of fresh blood in stool, occuring mostly between 2-6 weeks of age.5,6 Some have reported symptoms beginning as early as the first day of life. ${ }^{7.8}$ Dietary proteins excreted in mother's milk induce an inflammatory response of the rectum and distal sigmoid colon referred to as allergic proctocolitis. ${ }^{9}$ Breastfed infants with allergic proctocolitis are generally "well appearing". Blood loss is typically modest but can occasionally produce anemia and/ or hypoalbuminemia. ${ }^{10,11}$

Additional laboratory studies are often unnecessary to make the diagnosis of allergic proctocolitis. A complete blood count may show mild eosinophilia but is not diagnostic. ${ }^{12,13 .}$ Absence of peripheral eosinophilia does not rule out allergic proctocolitis. Radiographic investigations can be performed if warranted to rule out other conditions, such as, necrotizing enterocolitis and Hirschsprung disease. In severe or protracted cases unresponsive to dietary modification, endoscopic evaluation may be required.

The first line of treatment for suspected allergic colitis is maternal elimination diet, avoiding the most likely allergen i.e.cow's milk protein. Mothers are instructed to eliminate one food or food group at a time. Most cases will improve within $72-96$ hours. ${ }^{4}$ For infants receiving cow's milk formula, switching to soy-based formula is often the first step in treatment. If symptoms do not resolve, or soy has already been determined to be a provoking allergen, a switch to an extensively hydrolyzed formula may be necessary. ${ }^{12}$. If the elimination diet is successful in controlling symptoms, no other action is required beyond standard care.

\footnotetext{
*Corresponding Author | Dr Suchita Shrestha Joshi, Department of neonatology, Nepal Mediciti Hospital | Email:suchitajoshi29@gmail.com Mobile: 9813256060
} 


\section{CASE REPORT}

A set of twins were born at 34 weeks of gestational age to a 36 year old mother with gestational diabetes. Twin 1 (female) weighed 2270 grams and twin 2 (male) weighed 2300 grams. Other than bubble CPAP support and intravenous antibiotics for the first 3 days of life, the twins had an uneventful stay in the neonatal intensive care unit (NICU). A commercial milk protein-based formula was initiated immediately after birth along with expressed maternal breast milk. Feeding was well tolerated and both babies were discharged on 5th day of life.

On 10th day of life, both babies presented with history of passage of large amount of fresh blood per rectum. There was no history of vomiting, abdominal distension or poor activity. Both twins had received intramuscular vitamin $\mathrm{K}$ injection soon after birth. On enquiry, mother gave history of regular intake of cow's milk. There was no family history of polyps, inflammatory bowel disease, cow's milk protein allergy, other gastrointestinal pathology or bleeding disorders. The parents were non-consanguineous.

Both babies were admitted in NICU for observation. On examination, Twin 1 had mild pallor, tachycardia, poor pulse volume and prolonged capillary refill time. Abdomen was slightly distended and soft with visible intestinal loops. Bowel sound was present. Twin 2 had normal vital signs and systemic examination was also normal.

Laboratory investigations were negative for sepsis and bleeding diathesis for both twins. Twin 1 had total white cell count: 9070/cumm, neutrophil: 56\%, lymphocyte: 34\%, eosinophil: $2 \%$, platelet count: 469000/cumm, hemoglobin: $12.7 \mathrm{gm} / \mathrm{dl}$, c-reactive protein:9.7 mg/l, activated partial thromboplastin time: 54 seconds and prothrombin time: 17.4 seconds. Twin 2 had total white cell count: $7550 /$ cumm, neutrophil: 30\%, lymphocyte: $47 \%$, eosinophil: $4.9 \%$, platelet count: 418000/cumm, hemoglobin: $13.2 \mathrm{gm} / \mathrm{dl}$, c-reactive protein $<5 \mathrm{mg} / \mathrm{l}$, activated partial thromboplastin time: 54 seconds and prothrombin time: 18.8 seconds. Both babies had negative blood cultures.

Twin 1 had significantly dilated large bowel in plain abdominal $x$ ray (Figure 1 ) which triggered a suspicion of malrotation or volvulus. Therefore, and urgent CT abdomen with contrast was done which showed extensive pneumatosis coli involving the entire length of colon (Figure 2). Volvulus and malrotation were ruled out.

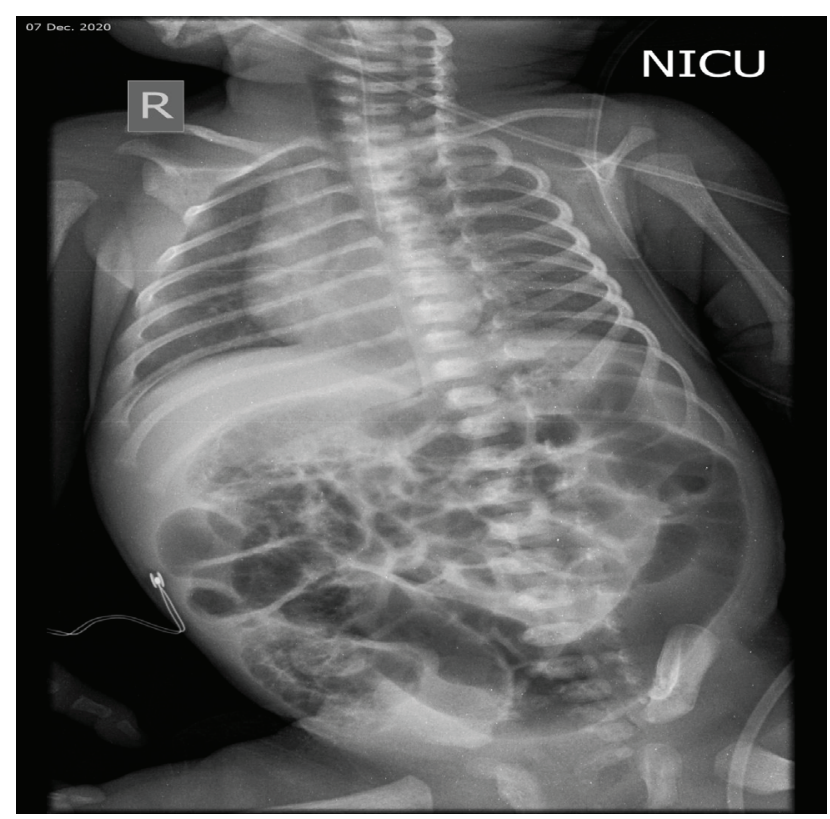

Figure 1: dilated large bowel in plain abdominal $x$ ray

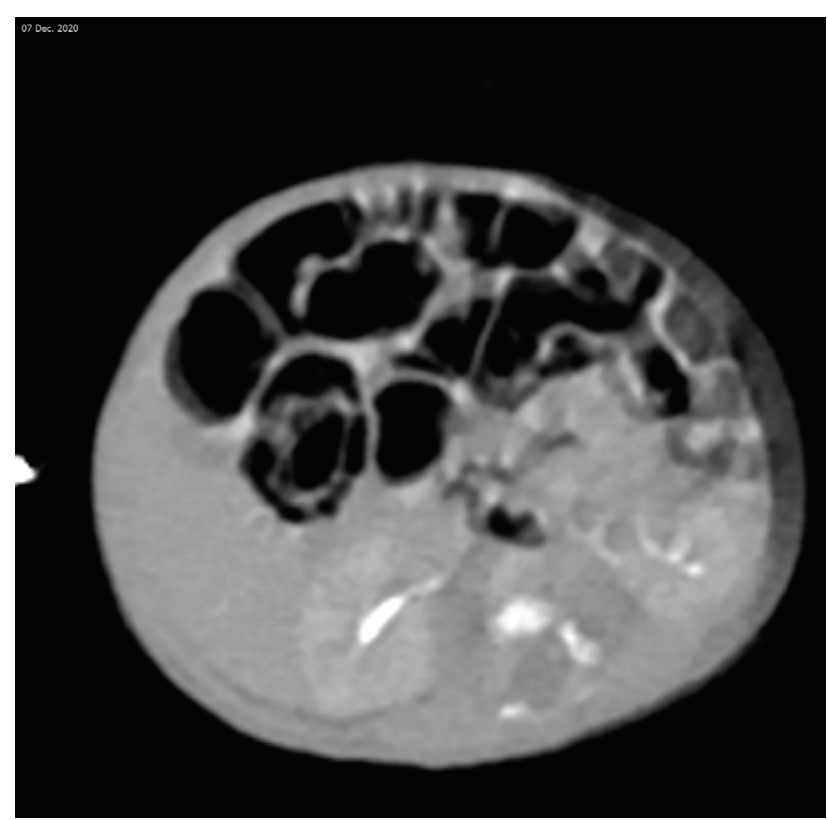

Figure 2: CT abdomen with contrast showing extensive pneumatosis coli involving the entire length of colon

Twin 2 also had dilated large bowels on plain abdominal $x$ ray. She had pneumatosis coli only on the ascending colon in the contrast CT scan of abdomen.

As twin 1 presented with features of shock, she received intravenous normal saline bolus and red cell transfusion, following which her clinical condition improved promptly. Both babies were kept nil by mouth and received intravenous fluids and intravenous antibiotics for five days. During this period, there were no further episodes of per-rectal bleeding and clinical condition remained stable. Repeat abdominal $x$-ray revealed significant improvement in dilatation of colon on both the babies. 
The clinical and radiological evidence of proctocolitis with normal inflammatory markers occurring simultaneously in twin infants, along with maternal history of intake of cow's milk prompted the diagnosis of cow's milk protein allergy proctocolitis.

The mother had been on dairy free diet as soon as the infants were admitted. On 6th day of admission, enteral feeding was initiated with expressed breast milk and hypo allergic formula. Both babies tolerated the enteral feeding well and there were no further episodes of per rectal bleeding. They were discharged on 7th day of admission. The mother was advised to remain on dairy free diet and continue breast feeding with top up of hydrolysed infant formula as required.

\section{DISCUSSION}

Gastrointestinal symptoms in neonates often cause concern for a serious underlying pathology. Underlying etiologies for 'bloody' stool include necrotizing enterocolitis, sepsis, or bleeding diathesis. In many cases, a thorough history and physical examination successfully rule out these conditions, and these neonates are often managed conservatively.

In this case, the twin babies presented with rectal bleeding during second week of life. Although this is not uncommon in ill, premature infants in the NICU, they were otherwise healthy. Bleeding occurred in both the twins after oral exposure to an antigen, cow's milk protein, suggesting the possibility of allergic colitis.

Hematochezia in infants can be caused by potentially lifethreatening disorders such as necrotizing enterocolitis, volvulus, gastroenteritis, sepsis, intussusception, and colitis complicating Hirschsprung disease ${ }^{14}$ but also due to benign conditions, such as anal fissure, rectal polyp or food protein allergy. In this case, the infants were clinically well and the laboratory investigations were also normal. CT scan of abdomen showed no features of malrotation or obstruction ruling out surgical causes of per rectal bleeding. In addition, an appropriate response to dietary elimination of cow's milk protein from mothers diet was demonstrated.

Management following a diagnosis of cow's milk protein allergic proctocolitis involves avoidance of the allergen. In breastfed infants, mothers should avoid all dietary sources of milk products for up to 2 weeks before expecting to see improvement in neonatal symptoms. ${ }^{15,16}$ In formula-fed infants, options for management include an elimination diet with extensively hydrolyzed infant formula or amino acidbased formula. ${ }^{17}$ In either case, resolution of symptoms is typically seen within 48 to 72 hours after the initiation of a cow's milk protein-free diet. ${ }^{18}$

\section{CONCLUSION}

Diagnosis of allergic colitis is based on exclusion of other causes of colitis and typical investigation findings. Moreover, a satisfactory response to dietary treatment must be demonstrated. This diagnosis should be considered in breast-fed infants with rectal bleeding without involvement of general health status.

\section{ABBREVIATIONS}

NICU: Neonatal intensive care unit

CT: Computed Tomography

\section{REFERENCES}

1. H A Sampson, S H Sicherer, A H Birnbaum. American Gastroenterological Association. AGA Technical Review on the Evaluation of Food Allergy in Gastrointestinal Disorders. Gastroenterology 2001;120:1026-1040.

2. Host A, Husby S, Osterballe O. A prospective study of cow's milk allergy in exclusively breast-fed infants. Incidence, pathogenetic role of early inadvertent exposure to cow's milk formula, and characterization of bovine milk protein in human milk. Acta Paediatr Scand 1988;77:663-670.

3. Lake AM. Food-induced eosinophilic proctocolitis. J Pediatr Gastroenterol Nutr 2000;30(Suppl):S58-S60.

4. Lake AM. Dietary protein enterocolitis. Immunol Allergy Clin North Am 1999;19:553-561

5. Lake AM Food Protein-Induced Proctitis, Enteropathy, and Enterocolitis of Infancy. UptoDate® 3.1. 2010.

6. Dupont C, Badoual J, Le Luyer B, et al. Rectosigmoidoscopic findings during isolated rectal bleeding in the neonate. J Pediatr Gastroenterol Nutr 1987;6:257-264.

7. Kumar D, Repucci A, Wyatt-Ashmead J, et al. Allergic colitis presenting in the first day of life: report of three cases. J Pediatr Gastroenterol Nutr 2000;31:195-197

8. Feiterna-Sperling C, Rammes S, Kewitz G, et al. A case of cow's milk allergy in the neonatal period-evidence for intrauterine sensitization? Pediatr Allergy Immunol 1997;8:152-155

9. Odze RD, Bines J, Leichtner AM, et al. Allergic proctocolitis in infants: A prospective clinicopathologic biopsy study. Hum Pathol 1993;24:668-674.

10. Sampson HA. Food allergy. J Allergy Clin Immunol 2003;11 1(2 Suppl): S540-S547.

11. Sampson HA. Update on food allergy. J Allergy Clin Immunol 2004 May; 113:805-819

12. Machida HM, Catto Smith AG, Gall DG, et al. Allergic colitis in infancy: Clinical and pathologic aspects. J Pediatr Gastroenterol Nutr 1994;19:22-26.

13. Winter HS, Antonioli DA, Fukagawa N, et al. Allergy-related proctocolitis in infants: Diagnostic usefulness of rectal biopsy. Mod Pathol 1990;3:5-10.

14. Odze R, Wershil B, Leichtner A, et al. Allergic colitis in infants. 
Allergic proctocolitis causing hematochezia in preterm twins... | Case Report

JPediatr 1995; 126:163-70.

15. Koletzko S, Niggemann B, Arato A, et al. Diagnostic approach and management of cow's-milk protein allergy in infants and children: ESPGHAN GI Committee Practical Guidelines. J Pediatr Gastroenterol Nutr. 2012;55: 221-229

16. Lozinsky AC, Morais MB. Eosinophilic colitis in infants.J Pediatr (Rio J). 2014; 90:16-21.

17. Susan SB, William JC, Frank RG, et al. American Academy of Pediatrics Committee on Nutrition Hypoallergenic Infant Formulas. Pediatrics 2000;106;346. DOI: 10.1542/ peds. 106.2.346

18. Kalayci O, Akpinarli A, Yigit S, Cetinkaya S. Intrauterine cow's milk sensitization. Allergy. 2000;55(4):408-409. 